Cuadernos de Historia Contemporánea

ISSN: 0214-400X

http://dx.doi.org/10.5209/CHCO.53659

\title{
Presentación
}

Jesus A. Martinez Martín

\section{[en] Foreword}

La Revista Cuadernos de Historia Contemporánea se aparta en esta ocasión de sus objetivos y contenidos habituales para dar cabida en un número de naturaleza extraordinaria a una veintena de aportaciones muy diversas, que tienen como punto en común contribuir al Homenaje a los profesores Octavio Ruiz-Manjón Cabeza y Juan Pablo Fusi Aizpurúa, con motivo de su jubilación académica.

El objetivo central de este número, no ha sido otro que el de reunir una serie de trabajos orientados de manera libre por sus autores al reconocimiento público de los dos profesores. Los dos han sido Catedráticos del Departamento, desde 1988 en el primer caso y desde 1986 en el segundo. Además, los dos han sido, directores de la Revista. La jubilación es un cambio en la situación administrativa, una situación convencional marcada por la edad que clausura las labores académicas, pero no la actividad intelectual e investigadora en plena madurez. Ni siquiera la jubilación, en estos dos casos, ha desligado a los dos profesores de la actividad académica, puesto que en la actualidad la han prolongado con su nuevo estatuto de Catedráticos Eméritos.

Es un gesto de consideración hacia quienes han desplegado su actividad académica durante más de treinta años en el Departamento de Historia Contemporánea y un reconocimiento intelectual a sus aportaciones en el panorama historiográfico. Aunque no hubo criterios previos en cuanto los autores de las colaboraciones en este número de la Revista, en la práctica todos, con alguna excepción, forman o han formado parte del Departamento, lo que convierte al número en un Homenaje de sus compañeros que compartieron o han compartido actividades docentes e inquietudes investigadoras.

Por su propia naturaleza y objetivos, el resultado en cuanto a contenidos es un especie de miscelánea. Los escritos han sido elaborados libremente por sus autores en cuanto a los temas y no han estado sujetos a los márgenes de un número monográfico, forma habitual que alimenta el contenido de la revistas universitarias, también el de Cuadernos de Historia Contemporánea, y tampoco han sido el resultado de un encargo previo para dotar de coherencia temática a la publicación. Responden a su objetivo, esto es, un espacio de encuentro de investigaciones reunidas con la suerte única de un Homenaje a los dos profesores. Desde esta perspectiva, el contenido de

1 Director del Departamento de Historia Contemporánea. Universidad complutense de Madrid (España) jamm@ghis.ucm.es 
los artículos es muy plural y heterogéneo. Pero, al mismo tiempo, están en sintonía con el estado actual de la historiografía, al menos en los territorios abordados en la actualidad desde el Departamento de Historia Contemporánea. El número retrata, en buena medida, la pluralidad historiográfica del Departamento y las líneas maestras en las que se desenvuelve su investigación. Desde luego las investigaciones del Departamento no se agotan aquí en cuanto a los temas y perspectivas, pero el repertorio es indicativo de los grupos de trabajo e investigaciones por las que discurren las preocupaciones historiográficas de sus miembros. La historia social en continuo diálogo con la historia política, la historia cultural y la historia de las relaciones internacionales son buena prueba de ello.

Las aportaciones de los homenajeados en el panorama historiográfico son diversas, teniendo en cuenta su dilatada carrera académica, pero no dejan de tener en común preocupaciones historiográficas de naturaleza generacional en la forma de hacer preguntas al pasado y las formas de resolverlas, tanto desde el punto de vista de los temas y sus cronologías como de los métodos para abordarlos. Un historia política y una historia intelectual, que dialogando entre ellas, tratan de explicar el siglo XX en España, contextualizada en el ámbito internacional, y con el foco puesto en el cambio de siglo XIX al XX y la crisis del 98, para estudiar las dimensiones políticas e intelectuales de esa historia, que en el caso de Octavio Ruiz-Manjón se prolonga hasta la guerra civil y en el caso de Juan Pablo Fusi todo el siglo XX. Una historia política narrada, tejida de fundamentos empíricos, que se preocupa por las ideas políticas, las formas de organización del poder y las posiciones críticas, los partidos políticos y los personajes, y una historia intelectual entendida como el producto cultural de las elites. Claro está que estas reflexiones exigirían muchos matices y no resumen sus trayectorias investigadoras, ni lo pretenden, y además cada uno de ellos tiene su propia singularidad historiográfica, pero ambas rescatan y enhebran acontecimientos de la vida política, dan voz a los personajes que protagonizan la narración, construyen relatos coherentes sobre problemas complejos y escapan de grandes elaboraciones teóricas.

$\mathrm{Su}$ obra historiográfica se puede apreciar en las dos primeras contribuciones al número: la entrevista que Carolina Rodríguez realiza a Octavio Ruiz-Manjón y la semblanza que Antonio López Vega hace de Juan Pablo Fusi. En el conjunto de textos, tres de ellos están elaborados a partir de estudios realizados por los dos homenajeados. César Antona recrea en Charlas sobre nacionalismo con Juan Pablo Fusi, una de los temas centrales de las investigaciones del profesor, mientras Luis Sala aborda Indalecio Prieto y el "problema vasco" (1930-1931) en sintonía con las aportaciones que Fusi ha realizado sobre los orígenes y evolución del nacionalismo vasco. Por su parte Oscar Bascuñán en Otro hombre bueno: historia de un republicano que protegió a personas en peligro durante la Guerra Civil, sigue las pautas del reciente libro de Octavio Ruiz-Manjón Algunos hombres buenos, sobre historias de vida de los que brindaron humanismo por encima de razones ideológicas y violencia durante la guerra civil. Son las dimensiones personales a las recurre el trabajo de Alicia Langa para evocar la figura historiográficamente considerada de Octavio Ruiz-Manjón. Y por su parte Emilio de Diego realiza una reflexión teórica sobre la historia y el papel del historiador en la actualidad, con la referencia metafórica al final de la historia y la situación de los eméritos.

Excepto tres contribuciones, todas están centradas cronológicamente en el siglo $\mathrm{XX}$, en sintonía y en proporción con el grueso de las preocupaciones investigadoras 
y de las inquietudes intelectuales de la historiografía española en los últimos años, estimulada por las nuevas generaciones de historiadores y cantera de alumnos interesados en la historia reciente. Todo ello detrimento de un siglo XIX que representó el centro de las preguntas de la historiografía de los años setenta y ochenta.

Desde el punto de vista temático y metodológico son varias las contribuciones que atienden a una historia social que abre, a su vez, variadas perspectivas de análisis. Es el tratamiento que, desde la historia urbana entendida como el diálogo entre el espacio y las gentes que lo habitan y lo transforman, Luis Enrique Otero ejemplifica en las transformaciones en Madrid durante el primer tercio del siglo XIX en claves de modernización. También en el mismo espacio temporal, Antonio Niño realiza un análisis sobre los fenómenos de opinión y su instrumentalización en la sociedad de masas, y también el del estudio sobre las elites, y en concreto la nobleza, como grupo social a partir de las referencias en las Guías y Anuarios de sociedad, que aborda José Miguel Hernández Barral. Una historia social y política de colectivos que en el caso de los emigrados polacos en la España de los años ochenta del siglo XX en España es tratada por José María Faraldo. Y Guadalupe Gómez-Ferrer realiza una comparación entre las escritoras Soledad Acosta Samper y Emilia Pardo Bazán adjudicándolas por sus obras y trayectorias vitales una referencia del feminismo en el siglo XIX. Es precisamente el estudio de las mujeres el sujeto central de las aportaciones de Elena Hernández Sandoica y de Marta del Moral. En el primer caso el sujeto mujer es abordado desde una reflexión teórica sobre su dimensión múltiple y los planteamientos de individualidad y subjetividad para abordar como un reto historiográfico el estudio de las mujeres y su acción, individual y colectiva. Sus reflexiones las proyecta, con ese reto que supone la biografía de las mujeres, sobre el caso de Rosario de Acuña. Por su parte Marta del Moral analiza la incorporación de las mujeres a la militancia socialista y del Partido Republicano Radical entre 1904 y 1910 como ingrediente de la modernización política y de sus tensiones.

Esta historia social en permanente diálogo con otras perspectivas de análisis abre la historia cultural como denominador común del segundo conjunto de trabajos que nutren el número de la revista. Desde el siglo XIX, Raquel Sánchez estudia los escritores emigrados españoles y sus actividades en Europa durante la monarquía isabelina. Y en el siglo XX, durante la posguerra, José María López Sánchez estudia los orígenes del Consejo Superior de Investigaciones Científicas como pieza central del discurso nacional-católico, Ana Martínez Rus las prácticas del régimen que mutilaron cualquier posibilidad de lectura libre, con censuras, quemas de libros y discursos católicos sobre malas lecturas y Rubén Pallol en Menéndez contra Menéndez la represión que le régimen desplegó sobre los discípulos y la tradición liberal de Menéndez Pidal y la imposición del discurso nacionalcatólico de Menéndez Pelayo y el control, de las cátedras de la Universidad. Y, en fin, con múltiples implicaciones interdisciplinares, Gutmaro Gómez Bravo y Ainhoa Campos se detienen en el estudio de la retaguardia madrileña durante la guerra civil y en concreto las dimensiones de la violencia y los abastecimientos. La historia política y en concreto el estalinismo es tratado a través de la fuente literaria, con la obra de Vasili Grossman, por Antonio Fernández García.

Un tercer bloque de colaboraciones está definido por la historia de las relaciones internacionales y de la políticas exterior de España. Rosario de la Torre se ocupa de la posición de España en los Tratados multilaterales de 1815, y ya en el siglo XX, José Antonio Montero estudia la neutralidad de Estados Unidos en la Gran Guerra 
a través de la revista España. Siguiendo el trazo cronológico que discurre por el siglo XX, Carlos Sanz estudia el papel de Alemania occidental como referente de la cultura crítica en España después de 1945, cruzando la historia política con unas relaciones internacionales culturalmente consideradas, mientras Juan Carlos Pereira y Manuel Fernández atienden al viaje y al discurso de Juan Carlos I en 1976 a Estados Unidos. Para cerrar Antonio Moreno abre el debate sobre la situación actual de la Unión Europea entendida como de crisis, centrando su naturaleza y aportando una perspectiva histórica.

Este número extraordinario ha sido posible por el concurso de muchas voluntades y de muchos esfuerzos. Para empezar por el de los coordinadores del número, José María Faraldo y de José Antonio Montero, Secretario actual de la Revista, así como el de su Directora, Elena Hernández Sandoica. Además el del Consejo de Redacción y la colaboración prestada por el personal investigador en formación: José Carlos Aránguez, Juan Bagur, Juan Pedro Bover, Ainhoa Campos, David del Castillo, Fernando García Naharro, Carlos Hernández Quero, Darío Migluicci, José Emilio Pérez Martínez, Alejandro Pérez Olivares y Zorann Petrovici. 